\title{
Efflux Time from Vertical Cylindrical Tank Design and Construction
}

\author{
Zeiad Algehani, Hatim AlOtaibi, Isam Al Zubaidi*, Hussameldin Ibrahim, Robert Jones \\ Industrial Systems Engineering, Faculty of Engineering and Applied Science, University of Regina \\ 3737 Wascana Parkway, Regina, SK \\ Isam.Al.Zubaidi@uregina.ca
}

\begin{abstract}
The efflux time measurement from vertical carbon steel vessel was measured using 1,2, and 3-pipe lines located at the bottom of the tank having different lengths and diameters. The efflux time experimental setup was developed and designed using Solid Edge software. The setup was built and commissioned at the University of Regina's Engineering Workshop and will be used to teach relevant engineering laboratory concepts at the undergraduate level. The experimental setup is equipped with pressure gauges, flow meters and level sensors necessary to collect meaningful data. The efflux time was measured for each configuration of length and diameter of exit pipes. The results obtained from the develop setup were analyzed and compared to relevant results available from the open literature.
\end{abstract}

Keywords: Efflux time, Design, Construction, Application

\section{Nomenclature}

\section{t: $\quad$ Efflux time}

Co: Discharge coefficient,

Ao: Area of orifice

A: Area of tank

$\mathrm{H}$ : Height of liquid at $\mathrm{t}=0$ and $\mathrm{h}$ is the height of the liquid at any time $\mathrm{t}$

gm: modified form of acceleration due to gravity

f: Friction factor

L: Length of the exit pipe

d: Diameter of the exit pipe

At: Cross sectional area of the tank

Ap: Cross sectional area of the pipe.

T: Thickness of tank (mm)

D: Nominal tank diameter (mm)

J: Joint efficiency

c: Corrosion Allowance ( $\mathrm{mm}$

F: Permissible Stress (MPa) 8.0 for PE80

C: Orifice cross-sectional area $\left(\mathrm{m}^{2}\right)$

Q: Volumetric Flow Rate $\left(\mathrm{m}^{3} / \mathrm{s}\right)$

$\mathrm{C}_{\mathrm{o}}$ : Orifice discharge coefficient

$\mathrm{h}$ : Height of the liquid above orifice (m)

\section{Introduction}

In most of the chemical and process plants, storage tanks appear in a large variety of geometrical shapes and capacities. The reasons for the choice of a given shape or geometry of a tank may be attributed to convenience, insulation requirements, floor space, material costs, corrosion, and safety considerations. The capacity of storage tanks is related to the required volumes for the feedstock materials as well as semi-finished, and finished products. The time required to gravity drain these vessels from their liquid contents is referred to efflux time (t) [1]. This knowledge is of critical 
importance in many emergency situations as well as productivity considerations. The general expression for efflux time is given by:

$$
t=\frac{1}{\operatorname{CoA} A o \sqrt{2 g}} \int_{0}^{H} \frac{A}{\sqrt{h}} d h
$$

Where Co is the orifice discharge coefficient with area of Ao, A is the area of the tank, $\mathrm{H}$ is the height of liquid at time equal to 0 and $\mathrm{h}$ is the height of the liquid at any time $\mathrm{t}$.

Mathematical analysis and experimental work for gravity draining of Newtonian fluid from a storage vessel through restricted orifice of different diameters has been studied [2]. It was shown that the acceleration of free surface of liquid is less than the acceleration due to gravity. Also, efflux time analysis from tanks with exit pipes and fittings in the Reynolds number range of 40000 - 60000 was studied [3]. The effect of pipes and fittings were expressed in terms of equivalent lengths. At Reynolds number of 6000, the maximum efflux time was 35 seconds [4]. The ratio of tank cross section to pipe cross section was 2228. This is much lower than the reported values of 5 and 6 obtained for efflux time analysis of a Newtonian liquid from cylindrical tank through a single exit pipe based on macroscopic balances. Hence, the efflux time equation could be simplified to the following expression:

$$
t=\sqrt{\frac{2}{g m}}\left(\sqrt{H+L}-\sqrt{H^{\prime}+L}\right.
$$

Where gm is modified form of acceleration due to gravity and is related to the acceleration due to gravity. $\mathrm{H}^{\prime}$ is the final height of liquid in the tank on draining and $\mathrm{L}$ is the length of the exit tube from the bottom of the tank. The relation between gm and acceleration due to gravity $\mathrm{g}$ is as follow:

$$
\frac{g m}{g}=\frac{1}{\left(1+4 f \frac{L}{d}\right)\left(\frac{A t}{A p}\right)^{2}}
$$

Where $\mathrm{f}$ is the friction factor, $\mathrm{L}$ and $\mathrm{d}$ are length and diameter of the exit pipe, $\mathrm{A}_{1}$ and $\mathrm{A}_{\mathrm{p}}$ is the cross sectional area of tank and pipe respectively. It was shown that the polymer solution increases the Froude number. Froude number can also increases by changing the geometry of the storage tank or by providing large diameter of exit pipe or providing multiple exit pipes. The mathematical analysis showed that the efflux time for cone shape vessel is less than that of cylinder through single exit pipe and the Froude number for cone was higher than that of a cylinder [7]. Reddy and Subbarao showed that efflux time for spherical tank is less than that of cylindrical tank [8]. An excellent review on the topic of efflux time from tanks has recently been conducted [9]. Kumar et al., concluded that the maximum deviation was found to be $19 \%$ and an average deviation of $16 \%$ between the experimental and theoretical values of the efflux time was observed [10].

\section{Experimental Setup Design}

The efflux time from vertical cylindrical tank was studied using in-house developed, designed and built efflux time equipment. The setup is designed to contain an acrylic storage tank located at the bottom of the steel construction and efflux tank at the top of the efflux tank steel structure. The water is pumped via a plastic tube, which equipped with pressure gauge, global valve, flow meter. Centrifugal pump was used to pump the water from the storage tank at the bottom of the construction to the efflux time tank that required to be emptied in very short time during special circumstances. The efflux time has a level sensor and level indicator to control and measure the level of liquid in the tank. The discharge water from the efflux tank was achieved by three different length, diameters, and roughness of pipes. Solid Edge software was used to design this setup. Four design options were studied and analyzed as follow: 


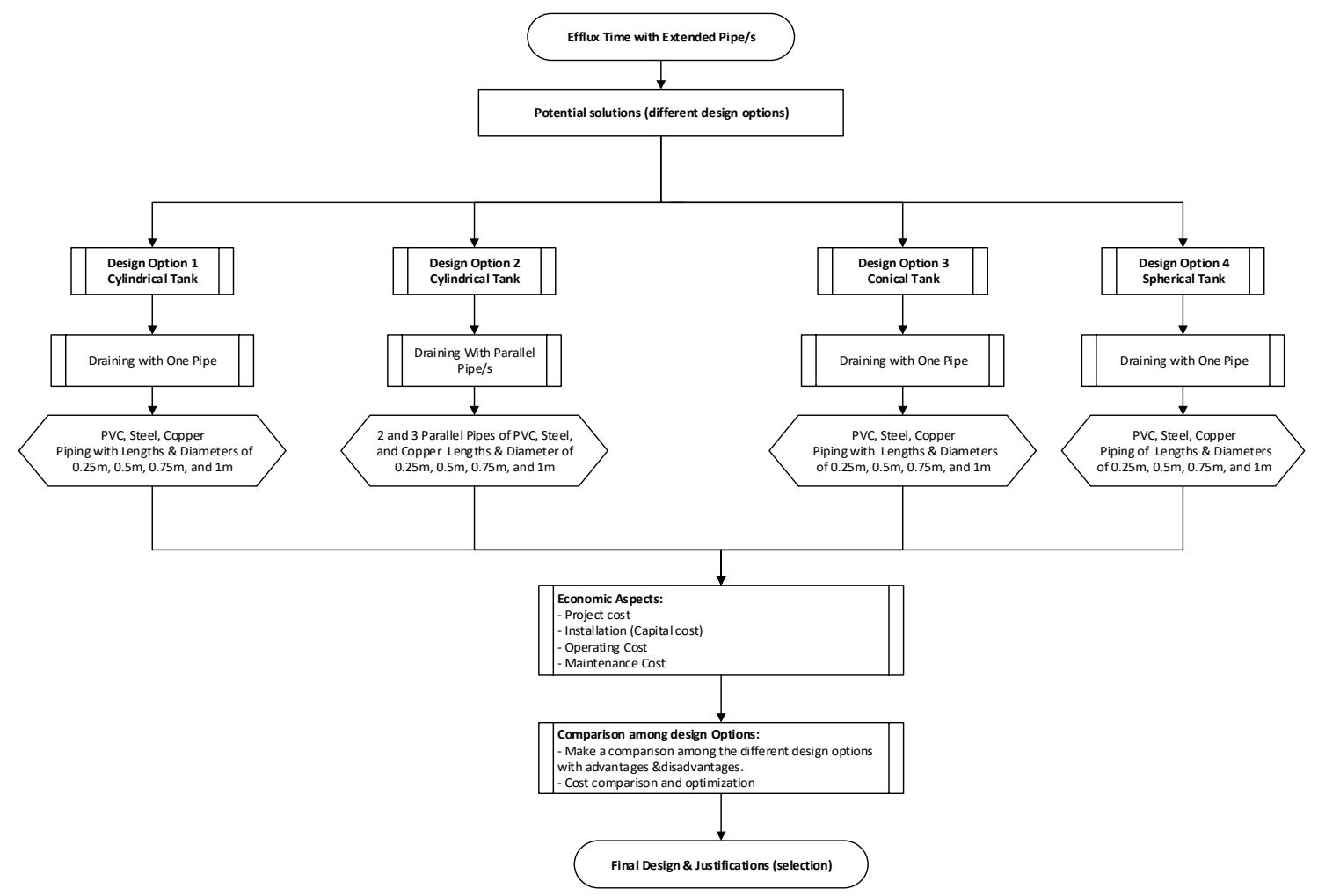

Fig. 1: Design options network diagram for efflux time.

\section{LAYOUT DIAGRAM FOR SYSTEM CONFIGURATION - 1}

LAYOUT DIAGRAM FOR SYSTEM CONFIGURATION - 2
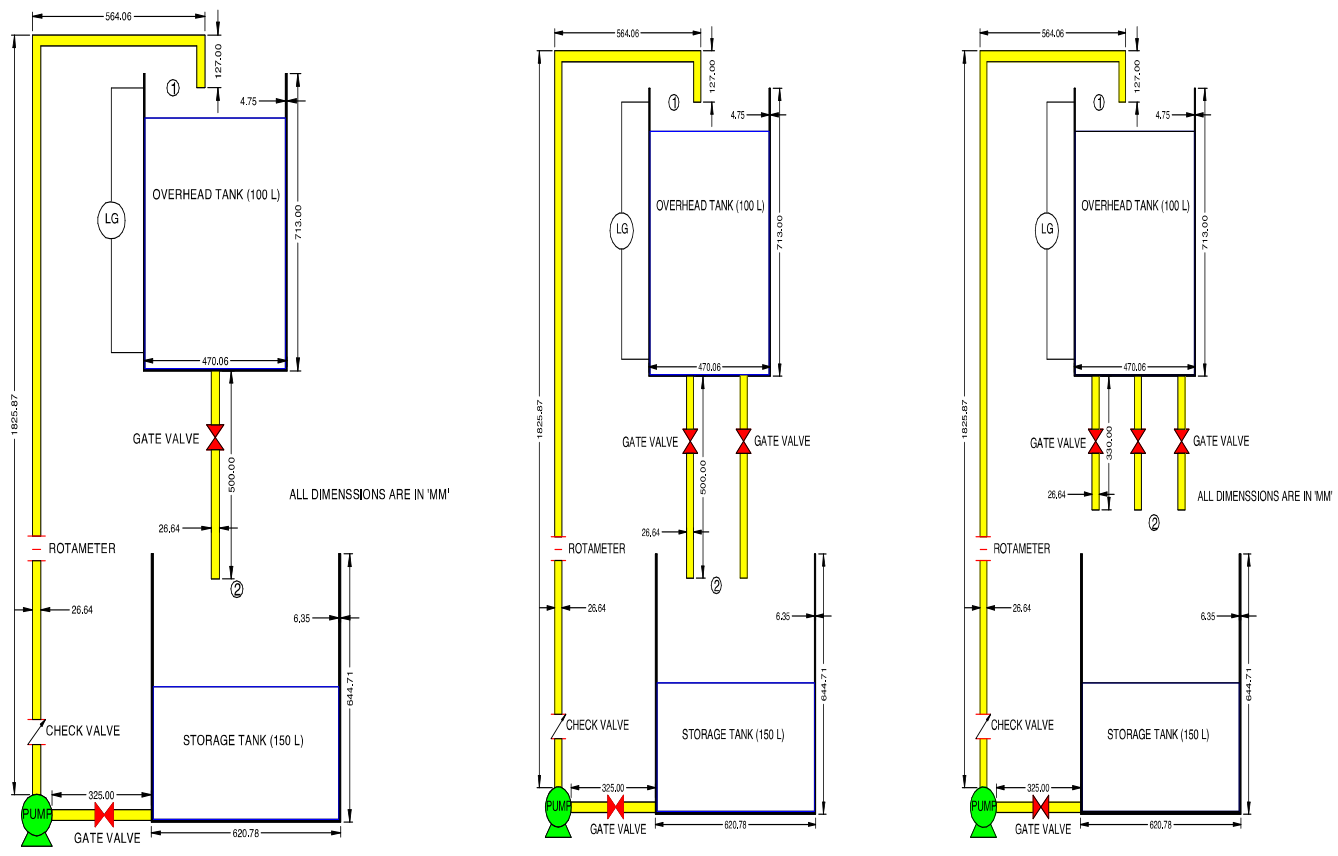

Fig. 2: Experimental setup for the three options. 


\section{Results and discussion}

Flow through one orifice:

The efflux time from cylindrical tank of diameter $460 \mathrm{~mm}$ and height $708 \mathrm{~mm}$ with liquid level $602 \mathrm{~mm}$ was used. The pressure inside the tank is the hydrostatic pressure of water $(\mathrm{P})$ can be calculated from the density of water $\rho$ and the height $\mathrm{z}$ as follows:

$$
\begin{gathered}
p_{a t m}=p g z \\
=\left(1000 \mathrm{~kg} / \mathrm{m}^{3}\right)\left(9.81 \mathrm{~m} / \mathrm{s}^{2}\right)(0.602 \mathrm{~m}) \\
=5906 \mathrm{~Pa}
\end{gathered}
$$

and
$T=\frac{P \cdot d}{2 \cdot F \cdot J}+C$
(Refer ASTM D1998 for poly ethylene storage tanks)
$\mathrm{T}=0.17$

The flow rate through an orifice is given as:

$$
Q=a \cdot C_{V o} \cdot \sqrt{2 \cdot g \cdot h}
$$

For a tank with constant cross-sectional area, $Q=-A t \cdot \frac{d h}{d t}$

$$
\begin{aligned}
& -A t \cdot \frac{d h}{d t}=a \cdot C_{o} \cdot \sqrt{2 \cdot g \cdot h} \\
& t=\frac{A t}{a C_{o} \sqrt{2 g}} \cdot 2 \sqrt{h} \\
& t=\frac{\frac{\pi}{4} d_{\text {tank }}^{2}}{\left(\frac{\pi}{4} d_{\text {orifice }}^{2}\right)\left(C_{v}\right)(\sqrt{2 g})} \cdot 2 \sqrt{h}
\end{aligned}
$$

Solving the above equation, $\mathrm{t}=117.25$

Thus, the time required emptying the tank is 121.25 seconds.

\section{Flow through two orifices:}

The flow rate through two orifices is given as $Q=2 \cdot a \cdot C_{o} \cdot \sqrt{2 \cdot g \cdot h}$

Thus, $\frac{d h}{d t}=\frac{2 \cdot a \cdot C_{o} \cdot \sqrt{2 \cdot g \cdot h}}{-A t}$

Solving the above differential equation, $\mathrm{t}=58.62$

\section{Flow through three orifices:}

The flow rate through three orifices is given as $Q=3 \cdot a \cdot C_{o} \cdot \sqrt{2 \cdot g \cdot h}$

Thus, $\frac{d h}{d t}=\frac{3 \cdot a \cdot C_{o} \cdot \sqrt{2 \cdot g \cdot h}}{-A t}$

Solving the above differential equation, $\mathrm{t}=39.08$

\section{Draining with one pipe:}

Case-1: Considering PVC pipe of length $0.25 \mathrm{~m}$

The modified Bernoulli equation including $\mathrm{K}$ - factors for fittings and friction factor for pipes can be written as:

$$
\frac{P_{1}}{\rho g}+\frac{V_{1}^{2}}{2 g}+Z_{1}=\frac{P_{2}}{\rho g}+\frac{V_{2}^{2}}{2 g}+Z_{2}+\sum\left(\frac{f L}{D_{h}}+K\right) \frac{V_{2}^{2}}{2 g}
$$


For fully open gate valve, $\mathrm{K}=0.15$, for square edge inlet, $\mathrm{K}=0.5$ and for sudden expansion to atmosphere, $\mathrm{K}=1.0$, thus total $\mathrm{K}-$ value $=1.65$. The roughness coefficient of PVC pipe, $\varepsilon=0.002 \mathrm{~mm}$. Thus, for pipe friction calculation the Haaland equation is given as:

$$
f=\left\{-0.782 \ln \left[\frac{6.9}{R e}+\left(\frac{\varepsilon}{3.7 \mathrm{~d}}\right)^{1.11}\right]\right\}^{-2}
$$

Consider the below table for PVC pipe ID. Initially consider pipe ID to be $8.74 \mathrm{~mm}$ and liquid level as $602 \mathrm{~mm}$. From fig: $1(\mathrm{a}), \mathrm{P}_{1}=\mathrm{P}_{2}=\mathrm{P}_{\mathrm{atm}}$ and that if $\mathrm{Z}_{2}=0, \mathrm{Z}=0.852 \mathrm{~m}$. The reservoir surface velocity $\mathrm{V}_{1}$ is given by the continuity equation as:

$$
A_{1} V_{1}=A_{2} V_{2}=>V_{1}=\left(\frac{A_{2}}{A_{1}}\right) V_{2}\left(\text { Consider, } V_{2}=V\right)
$$

Where, $A_{1}$ is the c/s area of tank and $A_{2}$ is the c/s area of pipe.

Because all the piping is of same diameter, the Bernoulli equation becomes,

$$
\begin{array}{r}
\left(\frac{A_{2}}{A_{1}}\right)^{2} \frac{V^{2}}{2 g}+Z_{1}=\frac{V^{2}}{2 g}+\left(\frac{f L}{D_{H}}+\sum K\right) \frac{V^{2}}{2 g} \\
\mathrm{~d}=\mathrm{ID}=0.00874 \mathrm{~m} \text {. Thus, } V=\left(\frac{16.716}{2.649634+28.60412 f}\right)^{0.5}
\end{array}
$$

Since, $\mathrm{V}$ and $\mathrm{f}$ are unknown it will be solved by trial and error method with an initial guess of $\mathrm{f}=0.0001$ and comparing with the Haaland equation, the velocity comes out to be $2.223 \mathrm{~m} / \mathrm{s}, \mathrm{f}$ is 0.025614 and the Reynolds number is coming out to be, $\operatorname{Re}=21732.73$; Thus, flow is turbulent.

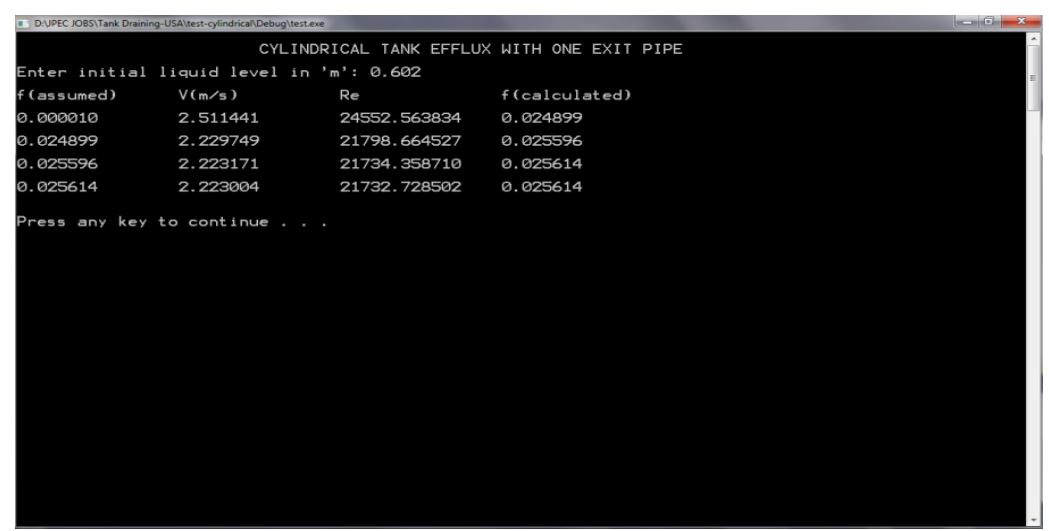

Fig. 3: Iteration of friction factor in Visual C++2010.

The mass balance equation is given as:

$$
\frac{d}{d t}\left(\rho \frac{\pi}{4} D^{2} h\right)=-\left(\rho \frac{\pi}{4} d^{2} V\right)
$$

Integrating the above equation we get,

$\Delta h=-0.00036 * V * \Delta t$

Taking a step size $\Delta t=0.01 \mathrm{~s}$ we get,

$\Delta h=-0.00000802 \mathrm{~m}=-0.00802 \mathrm{~mm}$ 
Thus $h=h+\Delta h=601.992 \mathrm{~mm}$. Putting this value of ' $\mathrm{h}$ ' again in previous equations gives a new ' $\mathrm{h}$ ' again. This process is continued in Excel till the tank is emptied. Thus, by applying all the above equations for different diameters as in given table 1 . The calculated efflux time is shown in table 2.

Table 1: ASTM standard diameters.

\begin{tabular}{|c|c|}
\hline Nominal Diameter (in) & Internal Diameter $(\mathrm{mm})$ \\
\hline 0.25 & 8.74 \\
\hline 0.50 & 15.80 \\
\hline 0.75 & 20.93 \\
\hline 1.00 & 26.64 \\
\hline
\end{tabular}

Table 2: Calculated efflux time from vertical cylindrical tank.

\begin{tabular}{|c|c|c|}
\hline Ser. No. & Internal Diameter, $(\mathrm{mm})$ & Efflux Time, $(\mathrm{s})$ \\
\hline 1. & 8.74 & 980.92 \\
\hline 2. & 15.80 & 281.38 \\
\hline 3. & 20.93 & 157.42 \\
\hline 4. & 26.64 & 96.05 \\
\hline
\end{tabular}

Case-2: Considering PVC pipe of length $0.5 \mathrm{~m}$

By changing the length to 0.5 meter in equations provided in case- 1 , the following results are obtained.

Table 3: PVC pipe exit with $0.5 \mathrm{~m}$ length.

\begin{tabular}{|c|c|c|}
\hline S.No. & $\begin{array}{c}\text { Internal Diameter } \\
(\mathrm{mm})\end{array}$ & $\begin{array}{c}\text { Efflux Time } \\
(\mathrm{s})\end{array}$ \\
\hline 1. & 8.74 & 875.72 \\
\hline 2. & 15.80 & 240.46 \\
\hline 3. & 20.93 & 132.65 \\
\hline 4. & 26.64 & 80.19 \\
\hline
\end{tabular}

Case-3: Considering PVC pipe of length $0.75 \mathrm{~m}$

By changing the length to 0.75 meter in equations provided in case- 1 , the following results are obtained.

Table 4: PVC exit pipe with $0.75 \mathrm{~m}$ length.

\begin{tabular}{|c|c|c|}
\hline S.No. & $\begin{array}{c}\text { Internal Diameter } \\
(\mathrm{mm})\end{array}$ & $\begin{array}{c}\text { Efflux Time } \\
(\mathrm{s})\end{array}$ \\
\hline 1. & 8.74 & 821.57 \\
\hline 2. & 15.80 & 218.28 \\
\hline 3. & 20.93 & 119.03 \\
\hline 4. & 26.64 & 71.39 \\
\hline
\end{tabular}

Case-4: Considering PVC pipe of length $1 \mathrm{~m}$

By changing the length to 1.0 meter in equations provided in case 1 , the following results are below. 
Table 5: PVC pipe with 1 m length.

\begin{tabular}{|c|c|c|}
\hline S.No. & $\begin{array}{c}\text { Internal Diameter } \\
(\mathrm{mm})\end{array}$ & $\begin{array}{c}\text { Efflux Time } \\
(\mathrm{s})\end{array}$ \\
\hline 1. & 8.74 & 787.77 \\
\hline 2. & 15.80 & 203.91 \\
\hline 3. & 20.93 & 110.12 \\
\hline 4. & 26.64 & 65.58 \\
\hline
\end{tabular}

For PVC pipes with different length and diameters the following graph is obtained.

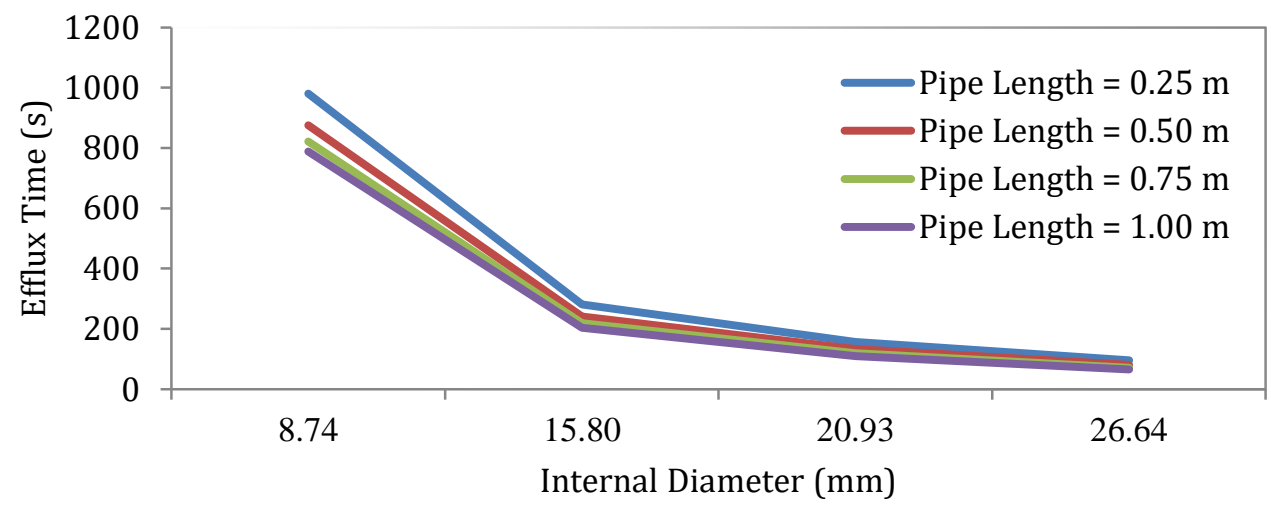

Fig. 4: Profile for PVC Pipe.

Case-5: Considering Steel pipe of length $0.25 \mathrm{~m}$

The roughness coefficient of a commercial steel pipe, $\varepsilon=0.045 \mathrm{~mm}$ and rest all the equations are same as described in case-1.

\section{Conclusion}

The efflux time from different storage tank configurations was studied. The vertical cylindrical tank setup was adopted for design, fabrication, commissioning, and successful operation. The study was extended to study the effect of many variables such as using different exit pipe diameters, length, and roughness of the inner surface of the pipe. Many trials were performed for each of the above variables.

\section{Acknowledgement}

The authors would like to thank the University of Regina, Program of Industrial System Engineering for providing all the facilities to achieve this work.

\section{References}

[1] W.P. Hart and T. Sommerfeld, "Expression for gravity drainage of annular and toroidal containers," Process Safety Progress, vol. 14, no. 4, pp. 238-243, 1995.

[2] J.N. Libii, "Mechanics of slow draining of a large tank under gravity," American Journal of Physics, vol. 71, no. 11, pp. 1204-1207, 2003.

[3] D.B. Von Dogen and Jr. E Roche, "Efflux time from tanks with exit pipes and fittings," International Journal of Engineering Education, vol. 15, no. 3, pp. 206-212, 1999.

[4] K.R. Morrison, "Modeling and computation techniques for fluid mechanics experiments," International Journal of Engineering Education, vol. 17, no. 3, pp. 288-293, 2001. 
[5] Ch. Subbaraoch, P. King, and V.S. Prasad, "Effect of polymer additions on the mechanics of slow draining of large tank under gravity," ARPN Journal of Engineering and Applied Sciences, vol. 3, no. 1, pp. 68-83, 2008.

[6] Ch. V. Subbarao, P. King, and V. S. Prasad, "Effect of polymer additives on the Dynamics of a Fluid for once through system," International Journal of Fluid Mechanics Research, vol. 35, no. 4, pp. 374-393, 2008.

[7] Ch. V. Subbarao, "Comparison of Efflux Time between Cylindrical and Conical Tanks Through an Exit Pipe," International Journal of Applied Science and Engineering, vol. 9, no. 1, pp. 33-41, 2011.

[8] G.V. Reddy and Ch.V. Subbarao, "Comparison of Efflux Times between cylindrical and spherical tank through an exit pipe," International Journal of Applied Science and Engineering, vol. 3, no. 2, pp. 61-68, 2011.

[9] CH. V. Subbarao, P. Srinivasa Rao, G. M. J. Raju, and V. S. Prasad, "Review on efflux time," Int. J. Chem. Sci., vol. 10, no. 3, pp. 1255-1270, 2012.

[10] G. Santosh Kumar, Ch. V. Subbarao, and P. King, "Efflux Time for Two Exit Pipe System," International Journal of Applied Science and Engineering, vol. 9, no. 4, pp. 277-286, 2011. 